Case report

https://www.journal-imab-bg.org

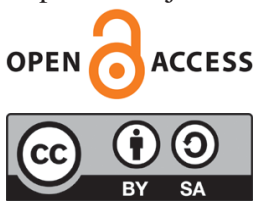

\title{
VESTIBULOPLASTY IN AN EXTREMELY ATROPHIC EDENTULOUS MANDIBLE USING A COMBINATION OF STRIP PALATAL GRAFT AND XENOGENEIC COLLAGEN MATRIX: A CASE RE- PORT
}

\author{
Tasho Gavrailov, Ivan Chenchev. \\ Department of Oral Surgery, Faculty of Dental Medicine, Medical University - \\ Plovdiv, Bulgaria.
}

\begin{abstract}
Purpose: The aim of this research was to evaluate the cumulative effect of using both epithelial autograft and xenogeneic collagen matrix as an alternative to single keratinized epithelial palatal autografts, which can prove beneficial for its reduced morbidity.

Materials and methods: This study includes one female patient with an extremely atrophic mandible who requires deepening of the vestibulum in the anterior region in order to improve the stability of the removable denture. The surgical procedure included local anesthesia, one horizontal incision and a partial-thickness flap elevation. The exposed periosteum was covered by a small keratinized epithelial autograft from the hard palate at its apical aspect and a xenogeneic collagen matrix at its coronal portion. Follow up of the healing process was performed on the 7 th, 14th, 30th day, after three and six months.

Results: The postoperative period underwent without any complications in all areas. The healing process resulted in the formation of an additional area of keratinized mucosa - a mean gain value of $2.92 \mathrm{~mm}$ after six months, which led to a significant improvement of denture stability.

Conclusion: The final result suggested that this technique shows great promise in compensating the disadvantages of using single grafting materials: the increased morbidity caused by the additional surgical site on the palate in the case of autografts and the greater shrinkage of the area of keratinized mucosa in a six months period when collagen matrixes are applied as a single grafting material in large edentulous areas.
\end{abstract}

Keywords: Vestibuloplasty, free epithelial graft, collagen matrix.

\section{INTRODUCTION}

Vestibuloplasty is defined as a surgical procedure on the soft tissues of the upper or lower jaw. The purpose of this technique is to correct the insufficient depth of the vestibulum and the limited amount of keratinized gingiva. $[1,2]$
Excessive bone loss due to traumatic exodontia, bone resorption secondary to periodontitis, and alveolar ridge atrophy following extractions play an important role in the loss of vestibular height in patients with completely edentulous jaws. [3]

Prosthetic treatment of such patients presents a great challenge for clinicians because the continuous resorption of the alveolar process impairs complete dentures' stability and function. The reduced retention of the complete dentures increases the resorption furthermore. [4] If vestibuloplasty is performed, it significantly increases the outcome of the treatment with complete removable dentures [5]

The method of Clark [6], described in 1953, was later modified, and different types of grafting materials were proposed. The vestibuloplasty procedure using the palatal mucosal autograft technique is a predictable treatment with minimal relapse and show favorable long-term outcomes. It is considered a gold standard in grafting materials, and every new material is to be compared to it. This procedure has several disadvantages, including increased patient morbidity, especially at the donor site on the palate and sometimes compromised esthetics of the final result. [7, 8]

A variety of grafting materials and techniques have been described since the Berlin consensus, which postulated that Clark's technique application should not leave an exposed periosteal site on the alveolar process to heal on secondary intention, but a graft should be applied. [9]

The recent introduction of the xenogeneic collagen matrixes as an alternative to keratinized mucosal autografts and the emerging scientific data suggesting that they can successfully reduce the need for autograft harvesting led to the increased application of collagen matrixes in vestibuloplasty. $[10,11]$ And even if this technique leads to satisfactory results when it comes to keratinized mucosa augmentation around dental implants $[12,13,14,15,16$, $17,18]$, it shows less predictable outcomes when used in larger areas after bone augmentation procedures or as a single grafting material in vestibuloplasty. That is why the modified strip technique procedure promises a combination of the benefits of the two types of grafts: the epithelial 
autograft and the xenogeneic collagen matrix while limiting their disadvantages. [19]

\section{MATERIALS AND METHODS}

The study included one patient with atrophic mandible, who was referred to the Department of Oral Surgery at the Faculty of dental medicine in Plovdiv for surgical treatment. The clinical examination revealed severe bone atrophy of the lower jaw, a shallow vestibulum, with an insufficient amount of keratinized mucosa. The diagnostic preoperative radiograph revealed less than $20 \mathrm{~mm}$ bone height in the anterior region (between the two mental foramina). She required a procedure of deepening the vestibulum in the frontal area of the lower jaw.

\section{Presurgical measurements.}

A silicone impression with a standard tray was taken, and a diagnostic model was prepared. A transparent surgical stent was fabricated by a dental technician, and the mucogingival line was marked on the stent intraorally, creating six holes in the stent in the anterior region of the mandible with a handpiece and a round metal burr. Coronary to these round holes, another six holes were made at the level of the top of the alveolar ridge. All holes $(1 \mathrm{~mm}$ in diameter) were marked with a surgical pen, the stent was removed and then adhesive was placed on the mucosa, and flowable composite material was placed on the marks, and then light-cured. (Fig. 1.)

Fig. 1. This photograph represents the exact size of the keratinized mucosa and the measuring points marked with flowable composite material

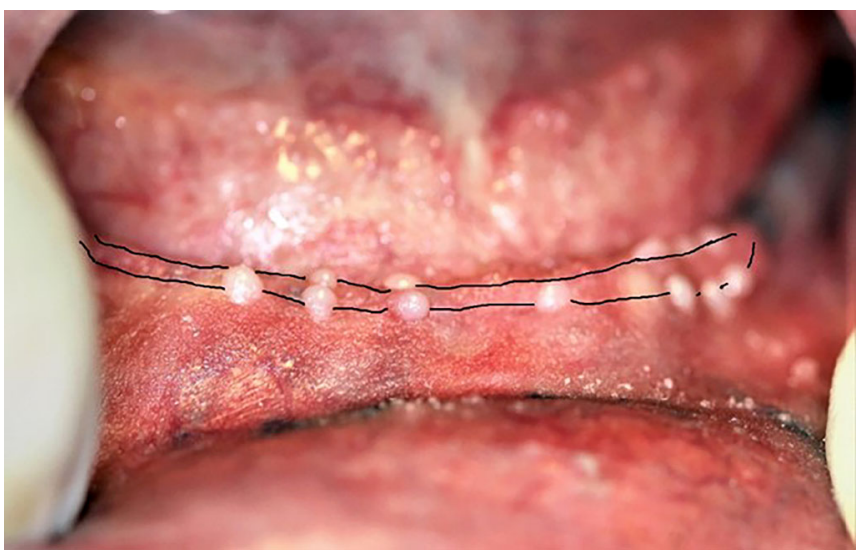

The positions of the holes marked the measuring points for the width of the keratinized mucosa in the anterior region of the mandible, which was then performed with a digital caliper before the composite was placed. With the composite fixed in the mouth, a parallel radiograph (OPG) was obtained Fig. 2. This protocol allowed the team to perform measurements of the amount of keratinized mucosa both clinically and digitally, based on the radiograph, because flowable composite is radio positive, and do it in ex- actly the same six points of the anterior mandible every time. Results were then assessed and compared.

Fig. 2. The radiograph shows the composite material. The distance between every two spots of composite material, which is actually the keratinized mucosa's width, can be measured on the radiograph.

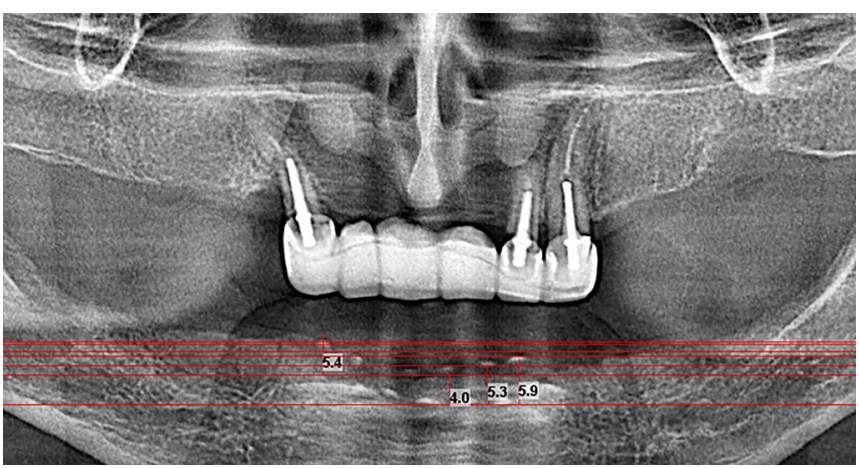

\section{Surgical treatment}

After performing nerve block technique in the mental foramen on both sides of the lower jaw as well as lingual anesthetic technique (Articaine 4\% with 1:200 000 epinephrine), the surgical intervention started with drawing a horizontal supraperiosteal incision on the border between keratinized and non-keratinized tissue - the mucogingival junction.

The flap was then elevated with a split thickness dissection to reposition the mucogingival line apically and suturing of the flap in this apical position with the use of T-mattress sutures (4-0 sutures). Fig. 3

Fig. 3. The supra periosteal dissection is performed, and the periosteum is exposed, the muscle fibers are displaced apically, and the new position of the mucosa is sutured.

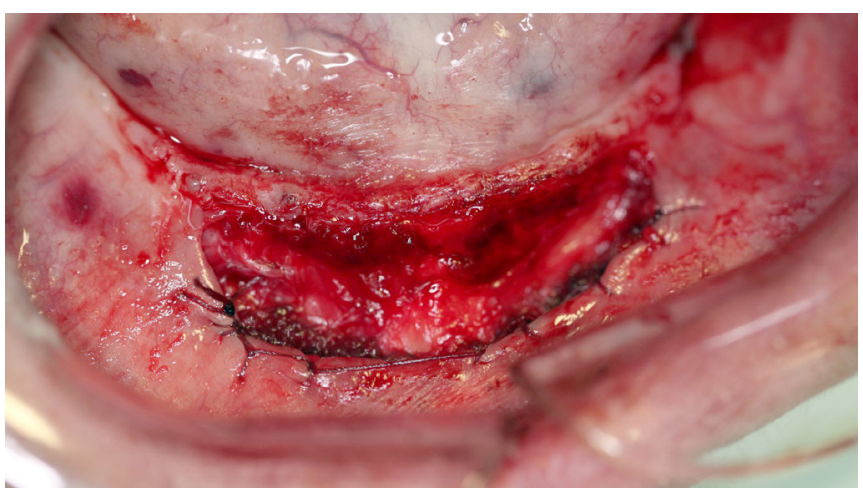

The resulting recipient site consisted of a periosteal bed that was smoothed using sharp dissection to avoid any loose fibers or irregularities. It was then measured with a sterile surgical caliper. Fig. 4. and 5. 
Fig. 4. Measuring the size of the recipient site

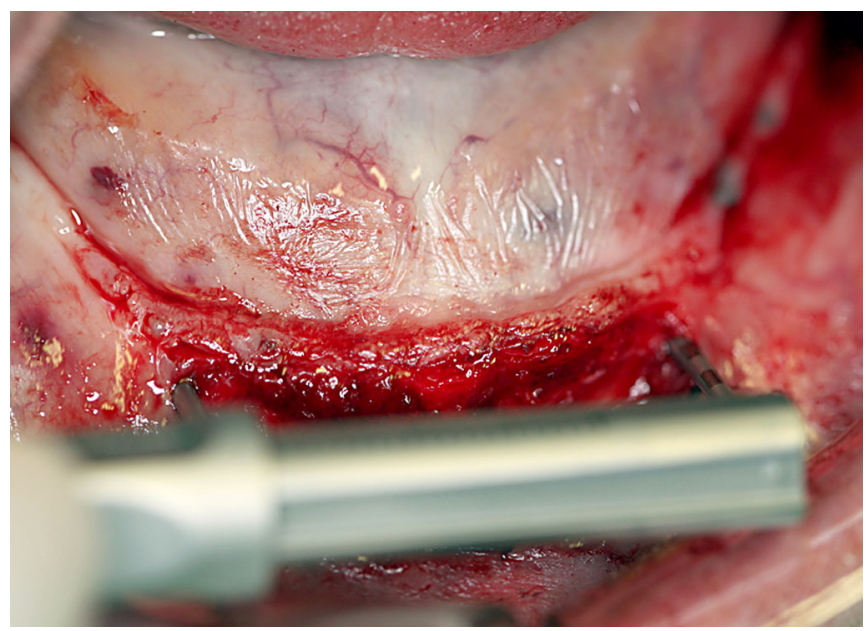

Fig. 5. The measured size is transferred to the second surgical site on the palate with the surgical caliper, making sure that the surgeon will harvest the exact amount of keratinized mucosa

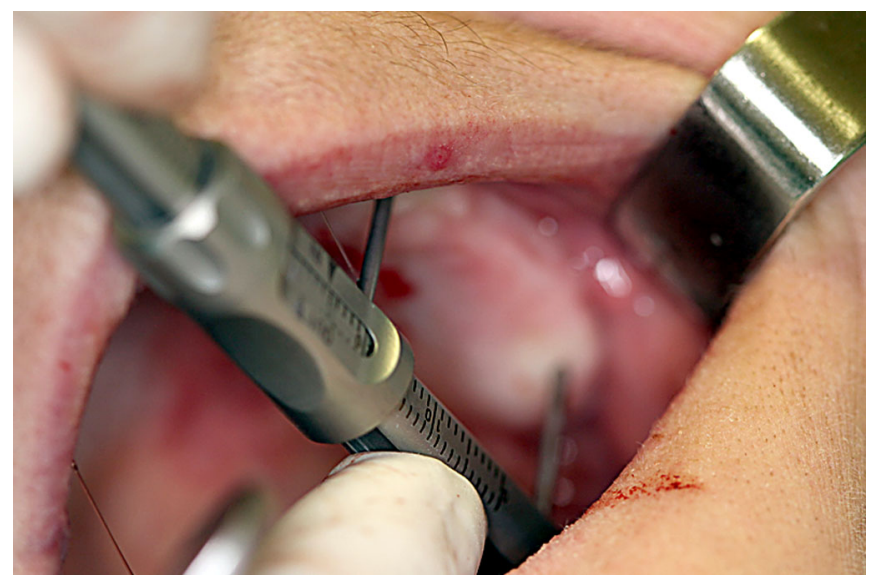

An autogenous free keratinized graft of appropriate length to cover the full apical extension of the recipient gingival bed was harvested from the palatal mucosa. This graft was only 2 to $3 \mathrm{~mm}$ wide and 1 to $1.5 \mathrm{~mm}$ thick (strip graft) and was sutured immediately after its retrieval to the apical end of the recipient bed with resorbable monofilament sutures (5-0 sutures). Fig. 6 and 7.

Fig. 6. The mucosal graft after excision and the collagen matrix open

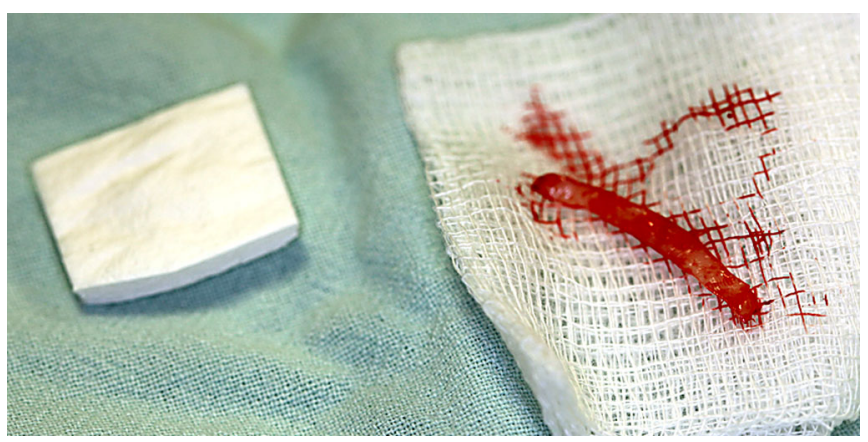

Fig. 7. The epithelial graft placed and sutured at the apical portion of the recipient site

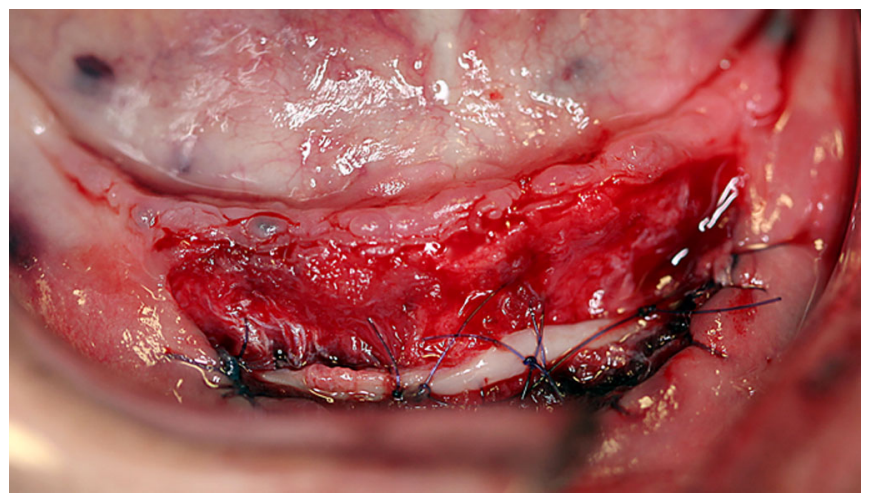

The remainder of the periosteal bed not covered with the strip graft was covered with the collagen matrixGeistlich Mucograft ${ }^{\circledR}$ (trimmed and customized for the available space) and sutured in place using the same resorbable suturing material by means of single interrupted and cross-mattress suture Fig. 8. The combination graft was left exposed for healing. The palatal wound was then closed using cross-mattress sutures, and, due to the limited width of the obtained grafts, an approximation of the palatal wound margins was achieved without any difficulty Fig. 9.

Fig. 8. The collagen matrix placed coronally to the epithelial graft and sutured

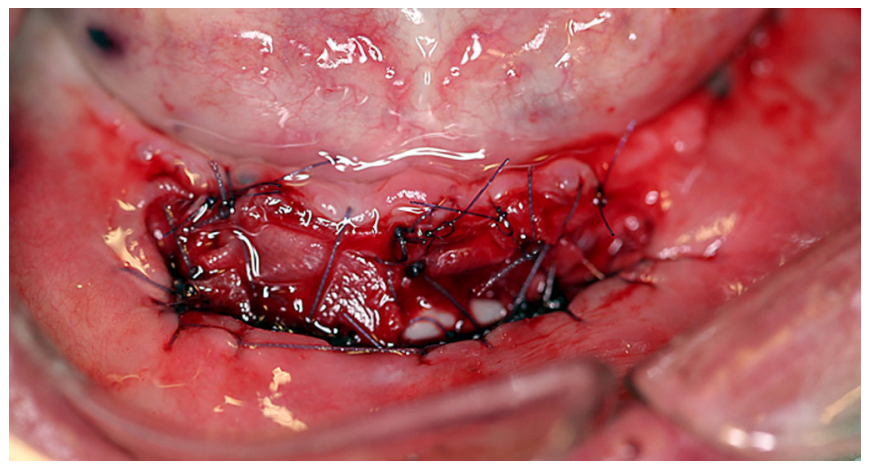

Fig. 9. Full closure and primary healing of the donor site

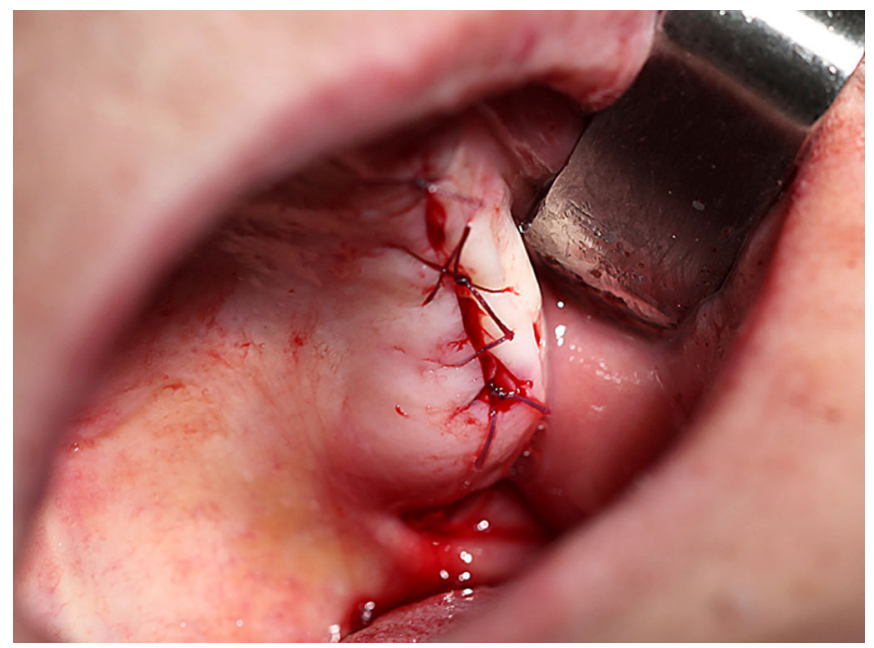




\section{Postoperative follow up}

After the surgery, the patient was put on a medication therapy that included oral intake of NAIDs (Aulin $0.10 \mathrm{~g}$ ) for a period of 3 days and irrigation of the oral cavity with $0.12 \%$ solution of chlorhexidine for 14 days. Follow up of the healing process was performed on the 7 th, 14th and 30th day, and measurements were performed after three and six months. Sutures were removed on the 14th day after the surgical procedure. No complications were observed during this period of time. The post-surgical pain was mild to moderate, especially in the donor area of the palate.

\section{RESULTS}

No complications were observed during the postsurgical healing period. The patient reported moderate post-surgical pain from the surgical site on the lower jaw and mild pain from the palatal wound. The diagnostic stent was placed in the patient's mouth, and the same measuring protocol was applied after one, three and six months. The esthetic outcome and the amount of keratinized tissue gained were satisfying- we measured a mean gain value of $2.92 \mathrm{~mm}$, as the least gain at one of the reference points was $1.0 \mathrm{~mm}$, and the most gain at another one was 4.50 $\mathrm{mm}$. These measurements were performed after six months, which makes the result sustainable. Fig. 10.

Fig. 10. The post-surgical result after six months. The line shows the newly gained amount of keratinized mucosa

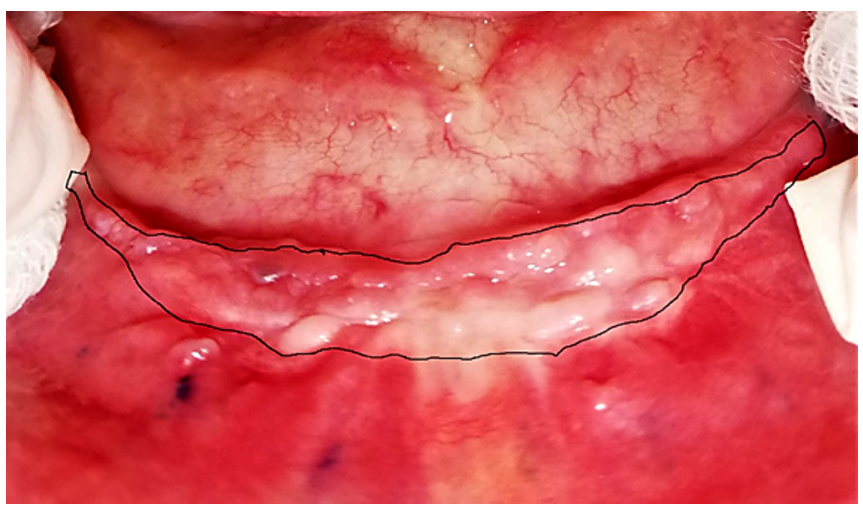

\section{DISCUSSION}

Alveolar bone resorption after exodontia leads to serious difficulties for prosthodontists, especially when treating a case with severe bone volume loss. [4] Preprosthetic surgery in general and vestibuloplasty in particular are meant to provide a better initial case and better prognosis of the prosthetic treatment. Autogenous palatal grafting procedures lead to predictable and long-lasting results, but their main disadvantages are the need for a second surgical site on the palate, thus, increased morbidity, and the compromised esthetics, due to the different color of the palatal mucosa $[5,6,7]$. A plethora of alternative grafting materials have been proposed during the last few decades with variable success rates, including dermal allografts, amnion allografts, xenogeneic collagen grafts $[11,14,15$, 18], PRF membranes [13], etc. Other studies suggest that we should use the classic grafting material - the free palatal graft, but to change the protocol of application [20,21].

There exists an increasing number of studies supporting the idea that collagen products are a promising alternative to autogenous soft tissue grafts. These products present good healing and vascularization, even when they heal on secondary intention[10, 17]. When collagen matrixes are used in keratinized mucosa increasing procedures around implants and natural teeth, the results are equal to those of autografts in split patient studies [18], but in larger surgical sites, such as edentulous areas after vertical and horizontal bone augmentation [19] or in vestibuloplasty of the anterior mandible the single use of a collagen matrix leads to less satisfying results, compared to the free palatal grafts. The aim of this case report pilot study was to assess the results from a technique that uses a combination of two grafts - a palatal strip graft and a xenogeneic collagen matrix. This technique was used before in a keratinized tissue augmenting procedure after surgical bone augmentation [19] but has not been reportedly applied in a classic vestibuloplasty procedure in the anterior region of the mandible.

\section{CONCLUSION}

This prospective case report study has shown that the combination of a xenogeneic collagen matrix and a free single strip gingival graft safely and effectively augmented the amount of keratinized mucosa, even in an initial situation of dramatic bone resorption in the frontal region of the mandible. These positive results, however, must be tested in well-designed clinical trials.

\section{REFERENCES:}

1. Atanasov D. (Editor). [Oral surgery.] [in Bulgarian] Tafprint, Plovdiv. 2011: 255-259.

2. Ivanova V, Chenchev I, Gavrailov T. Clinical Comparison of Three Methods for Vestibuloplasty in the Anterior Part of the Mandibule. $J$ of IMAB. 2018 Oct-Dec;24(4):22232227. [Crossref]

3. Archer MD. Discussion. In:
Electrochemistry in Research and Development. Kalvoda R, Parsons R. (authors) Springer, USA. 1985. pp.49-51. [Internet]

4. Kelsey CC. Alveolar bone resorption under complete dentures. $J$ Prosthet Dent. 1971 Feb;25(3):152-61. [PubMed]

5. de Koomen HA. A prosthetic view on vestibuloplasty with free mu- cosal graft. Int J Oral Surg. 1977 Feb;6(1):38-41. [PubMed]

6. Clark HB Jr. Deepening of labial sulcus by mucosal flap advancement. J Oral Surg (Chic). 1953 Apr;11(2): 165-8. [PubMed]

7. Amphlett J, Colwell WC. Edentulous vestibuloplasty using the palatal graft technique. J Prosthet Dent. 1982 Jul;48(1):8-14. [PubMed] 
8. Huybers TJ, Stoelinga PJ, De Koomen HA, Tideman H. Mandibular vestibuloplasty using a free mucosal graft. A 2-7 year evaluation. Int J Oral Surg. 1985 Feb;14(1):11-5. [PubMed]

9. Cawood JI, Stoelinga PJ, Blackburn TK. The evolution of preimplant surgery from preprosthetic surgery. Int J Oral Maxillofac Surg. 2007 May;36(5):377-85. [PubMed]

10. Ghanaati S. Non-cross-linked porcine-based collagen I-III membranes do not require high vascularization rates for their integration within the implantation bed: a paradigm shift. Acta Biomater. 2012 Aug;8(8): 3061-72. [PubMed]

11. Herford AS, Akin L, Cicciu M, Maiorana C, Boyne PJ. Use of a porcine collagen matrix as an alternative to autogenous tissue for grafting oral soft tissue defects. J Oral Maxillofac Surg. $2010 \mathrm{Jul} ; 68(7): 1463-70$. [PubMed]

12. Lim HC, An SC, Lee DW, Lee DW. A retrospective comparison of three modalities for vestibuloplasty in the posterior mandible: apically positioned flap only vs. free gingival graft vs. collagen matrix. Clinical Oral Investigations. 2018 Jun;22(5):21212128. [PubMed]

13. Mahajan M, Gupta MK, Bande C, Meshram V. Comparative Evaluation of Healing Pattern After Surgical Exci- sion of Oral Mucosal Lesions by Using Platelet-Rich Fibrin (PRF) Membrane and Collagen Membrane as Grafting Materials-A Randomized Clinical Trial. J Oral Maxillofac Surg. 2018; 76(7): 1469.e1-1469.e9. [PubMed]

14. Maiorana C, Pivetti L, Signorino F, Grossi GB, Herford AS, Beretta M. The efficacy of a porcine collagen matrix in keratinized tissue augmentation: a 5-year follow-up study. Int J Implant Dent. 2018 Jan 10;4(1):1. [PubMed]

15. Schmitt CM, Moest T, Lutz R, Wehrhan F, Neukam FW, Schlegel KA. Long-term outcomes after vestibuloplasty with a porcine collagen matrix (Mucograft ${ }^{\circledR}$ ) versus the free gingival graft: a comparative prospective clinical trial. Clin Oral Implants Res. 2016; 27(11):125-133. [PubMed]

16. Rastogi S, Modi M, Sathian B. The efficacy of collagen membrane as a biodegradable wound dressing material for surgical defects of oral mucosa: a prospective study. J Oral Maxillofac Surg. 2009 Aug;67(8):1600-6. [PubMed]

17. Preidl RHM, Wehrhan F, Weber M, Neukam FW, Kesting M, Schmitt CM. Collagen Matrix Vascularization in a Peri-Implant Vestibuloplasty Situation Proceeds Within the First Postoperative Week. J Oral Maxillofac
Surg. 2019 Sep;77(9):1797-1806. [PubMed]

18. Thoma DS, Alshihri A, Fontolliet A, Hämmerle CHF, Jung RE, Benic GI. Clinical and histologic evaluation of different approaches to gain keratinized tissue prior to implant placement in fully edentulous patients. Clin Oral Investig. 2018 Jun; 22(5):2111-2119. [PubMed]

19.Urban IA, Lozada JL, Nagy K, Sanz M. Treatment of severe mucogingival defects with a combination of strip gingival grafts and a xenogeneic collagen matrix: a prospective case series study. Int J Periodontics Restorative Dent. 2015 May-Jun; 35(3):34553. [PubMed]

20. Tarasenko S, Ashurko I, Taschieri S, Repina S, Esaya N A, Corbella S. Comparative analysis of methods to increase the amount of keratinized mucosa before stage-two surgery: a randomized controlled study. Quintessence Int. 2020; 51(5): 374-387. [PubMed]

21. Meitner S, Papadimitriou D, Kotsailidi EA, Habibzadeh M, Chochlidakis K, Ercoli C, et al. An alternative approach for vestibular extension using temporary coverage of epithelialized palatal grafts. Quintessence Int. 2020; 51(4):286-292. [PubMed]

Please cite this article as: Gavrailov T, Chenchev I. Vestibuloplasty in an extremely atrophic edentulous mandible using a combination of strip palatal graft and xenogeneic collagen matrix: A case report. J of IMAB. 2021 AprJun;27(2):3812-3816. DOI: https://doi.org/10.5272/jimab.2021272.3812

Received: 30/07/2020; Published online: 14/06/2021

\author{
Address for correspondence: \\ Tasho Gavrailov \\ Department of Oral Surgery, Faculty of Dental Medicine, Medical University - \\ Plovdiv, \\ 3, Hristo Botev Str., Plovdiv, Bulgaria \\ E-mail: tasho.gavrailov@gmail.com,
}

